\title{
Desain lansekap bantaran Tukad Badung sebagai ruang terbuka non hijau publik di Kota Denpasar
}

\author{
I Ketut Adikresna Handayana ${ }^{1}$, Naniek Kohdrata ${ }^{1 *}$, I Gusti Alit Gunadi²
}

1. Program Studi Arsitektur Pertamanan, Fakultas Pertanian, Universitas Udayana, Indonesia 80236

2. Program Studi Agroekoteknologi, Fakultas Pertanian, Universitas Udayana, Indonesia 80236

*E-mail: naniek_kohdrata@unud.ac.id

\begin{abstract}
Design of Badung riverscape as non-green public open space in Denpasar City. Tukad Badung Riverscape in Pemogan Village is one of the riverscape in Denpasar City which has the potential to be designed as a Non-green Public Open Space (NPOS). NPOS is a place that can be used for the people to do their activities or recreation. This study aims to find out the potentials, problems and produce a design concept of Tukad Badung Riverscape in the Pemogan Village. The method used in this study was field survey with observation techniques, interviews, and literature study. Stages of this research are inventory, analysis, and synthesis which at the same time is the foundation in making design. The results indicated it had potentials and problems exist in Tukad Badung were people activities and Tukad Badung has wide riverbanks, meanwhile the problems were accessibility, plant, land, cleanliness, and facilities. The concept of design produced in this research was Balinese natural metaphor that takes the form of rice field terraces and beach waves. Suggestions that can be given are suggestions or recommendations for the government of Denpasar City such as NPOS design.
\end{abstract}

Keywords : Badung Riverscape, design concept, metaphor, non-green public open space,

\section{Pendahuluan}

Kota Denpasar sebagai Ibukota Provinsi Bali merupakan salah satu kota besar di Indonesia memiliki masyarakat sebanyak 659.623 jiwa (Dinas Kependudukan dan Pencatatan Sipil Kota Denpasar tahun 2016). Kota Denpasar memiliki ruang terbuka berupa taman kota untuk rekreasi dan penyegaran sebagai wadah masyarakat yang sehari-harinya menjalankan aktivitas di kota. Ruang terbuka di Kota Denpasar seperti Lapangan Puputan I Gusti Ngurah Made Agung, Taman Kota Lumintang, dan Lapangan Niti Mandala Renon dengan berbagai fasilitas pendukung untuk melakukan berbagai aktivitas sehari-harinya ramai digunakan masyarakat.

Bantaran Tukad Badung di kawasan Desa Pemogan, Kota Denpasar memiliki potensi untuk dimanfaatkan sebagai ruang terbuka khususnya Ruang Terbuka Non Hijau Publik (RTNHP) sehingga diperlukan konsep desain bantaran yang dapat dijadikan sebagai RTNHP. Bantaran Tukad Badung di kawasan Desa Pemogan sehariharinya digunakan oleh masyarakat sebagai tempat melakukan aktivitas seperti memancing, olahraga, dan berekreasi bersama keluarga. Desain pada bantaran Tukad Badung diperlukan untuk mengembangkan bantaran sebagai RTNHP sehingga dapat memfasilitasi masyarakat dalam beraktivitas. Penataan serta pemanfaatan bantaran sungai sebagai RTNHP juga dapat menambah keberadaan ruang terbuka serta memperindah tampilan fisik kota.

Rumusan masalah pada penelitian ini yaitu apa potensi dan permasalahan yang terdapat di bantaran Tukad Badung serta bagaimana konsep desain Ruang Terbuka Non Hijau Publik pada bantaran Tukad Badung. Tujuan dari penelitian ini adalah mengetahui potensi dan permasalahan yang terdapat di bantaran Tukad Badung dan menghasilkan konsep desain RTNHP pada bantaran Tukad Badung. 


\section{Metode Penelitian}

\subsection{Tempat dan Waktu Penelitian}

Pelaksanaan kegiatan penelitian dilakukan di bantaran Tukad Badung, Desa Pemogan, Kecamatan Denpasar Selatan, Kota Denpasar, Provinsi Bali. Waktu penelitian dilakukan mulai bulan Juli 2016 sampai bulan Juli 2017.

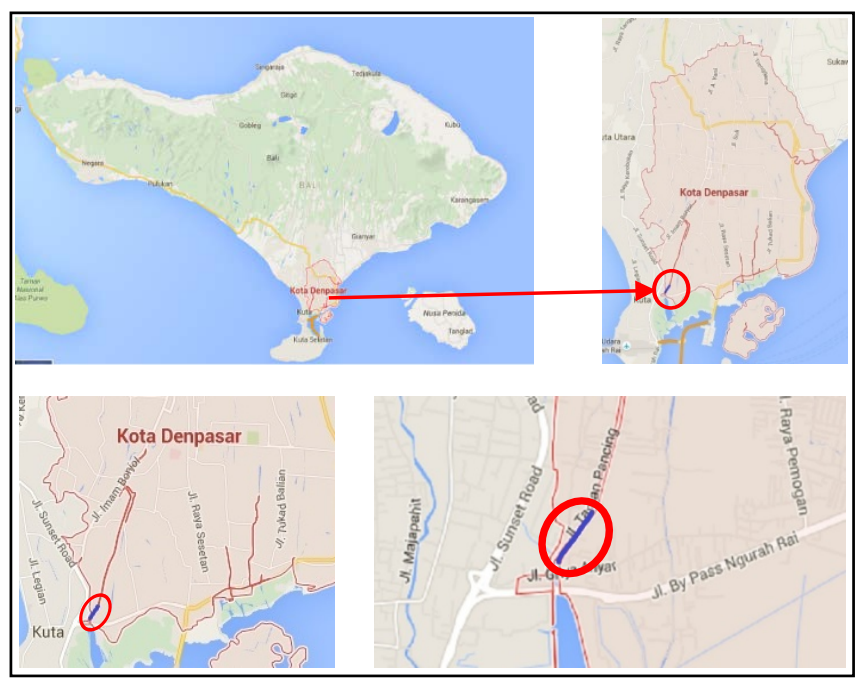

Gambar 1. Lokasi penelitian

\subsection{Alat dan bahan Penelitian}

Alat penelitian yang digunakan dalam penelitian ini adalah alat tulis dan gambar, meteran, kamera, lembar wawancara, dan laptop dengan perangkat lunak Google Earth, Autocad 2014, Google Sketchup 2015, dan Adobe Photoshop CS5.

\subsection{Metode Penelitian}

Penelitian dilakukan dengan metode survei dimulai dengan tahapan inventarisasi data yakni mengumpulkan data yang ada dan diperlukan mengenai tapak yang akan didesain. Kemudian dilanjutkan dengan analisis data yakni mangaitkan data yang terkumpul sehingga dapat diketahui potensi, kendala serta bahaya yang terdapat pada tapak atau lokasi penelitian, dan sintesis penyelesaian masalah dengan memanfaatkan potensi, mengatasi kendala, dan menghindari bahaya untuk menghasilkan konsep yang merupakan landasan dalam pembuatan desain sehingga memperoleh rencana desain.

\subsubsection{Data Penelitian}

Jenis data yang dikumpulkan dalam penelitian ini berupa data primer dan data sekunder. Data primer berupa pengumpulan data yang diperoleh melalui observasi dan wawancara. Data sekunder merupakan data yang diperoleh dari metode studi pustaka dari buku-buku, jurnal, majalah, dan internet.

\subsubsection{Metode Pengumpulan Data}

Metode pengumpulan data yang digunakan adalah observasi, wawancara, dan studi pustaka.

\section{Observasi}

Observasi merupakan teknik pengumpulan data dengan melakukan pengamatan secara langsung kondisi tapak baik administratif, fisik dan biofisik, fungsional, maupun pengguna untuk mengetahui keadaan dari bantaran Tukad Badung.

\section{Wawancara}

Wawancara merupakan teknik pengumpulan data dengan mengadakan tanya jawab langsung terhadap pihak-pihak yang berkaitan dengan penelitian yakni Balai Wilayah Sungai Bali-Penida dan pengguna mengenai hal-hal yang berkaitan dengan bantaran Tukad Badung seperti hidrologi sungai, fungsi tapak, dan pengguna. 
3. Studi pustaka

Studi pustaka merupakan metode pengumpulan data dengan mencari data-data yang berhubungan dengan penelitian ini baik diperoleh dari jurnal hasil penelitian, buku-buku, peraturan-peraturan, dan sumbersumber tertulis maupun media internet.

\subsection{Batasan Penelitian}

Penelitian ini dilakukan di bantaran Tukad Badung Desa Pemogan sepanjang $390 \mathrm{~m}$ dengan melakukan desain lansekap bantaran Tukad Badung yang dibatasi hingga konsep desain sebagai bentuk rekomendasi penataan bantaran sungai bagi pemerintah kota.

\section{Hasil dan Pembahasan}

\subsection{Kondisi Umum Bantaran Tukad Badung}

Bantaran Tukad Badung lokasi penelitian terletak di Desa Pemogan di Kecamatan Denpasar Selatan, Kota Denpasar, Provinsi Bali. Batas-batas tapak lokasi penelitian adalah kawasan Tukad Badung pada bagian utara, jembatan pada sebelah selatan, Jalan Taman Pancing pada sebelah barat, dan Gang Lestari pada bagian timur. Luas keseluruhan lokasi penelitian yaitu pada bantaran bagian barat memiliki luas sekitar 4.536 $\mathrm{m}^{2}$, sedangkan luas bantaran bagian timur sekitar $4.500 \mathrm{~m}^{2}$.

Bantaran Tukad Badung menggunakan material pekerasan yang terdiri dari beton dan bebatuan sebegai material talud (retaining wall) pada sisi bantaran dan sungai. Lokasi penelitian terdiri dari dua bantaran yaitu bantaran bagian barat dan bagian timur yang masing-masing terdapat jogging track, akses berupa tangga, akses kendaraan, dan vegetasi. Terdapat juga tapak yang terpisah dari tapak utama di selatan bantaran bagian barat.

Vegetasi yang terdapat di bantaran sebagian besar terletak di bantaran bagian barat. Jenis-jenis tanaman pada bantaran dapat dilihat pada tabel 1 .

Tabel 1. Jenis-jenis Tanaman pada Bantaran

\begin{tabular}{clcl}
\hline No & \multicolumn{1}{c}{ Nama Tanaman } & Jumlah & \multicolumn{1}{c}{ Lokasi } \\
\hline 1 & Bougainvillea spectabillis (Kembang Kertas) & 1 & Bantaran Barat \\
2 & Cerbera manghus (Bintaro) & 1 & Bantaran Barat \\
3 & Cocos nucifera (Kelapa) & 6 & Bantaran Barat \\
4 & Cordyline australis (Hanjuang) & 2 & Bantaran Barat \\
5 & Delonix regia (Flamboyan) & 48 & Bantaran Barat dan Timur \\
6 & Optunia spp (Kaktus) & 1 & Bantaran Barat \\
7 & Plumeria sp (Kamboja) & 3 & Bantaran Barat \\
8 & Wodyetia bifurcata (Palem Ekor Tupai) & 2 & Bantaran Barat \\
\hline
\end{tabular}

Supraptomardjo (1970) menunjukkan jenis tanah di Desa Pemogan yaitu latosol coklat kekuningan. Lokasi penelitian beriklim tropis dengan suhu udara berkisar antara $24,5^{\circ} \mathrm{C}-30,4^{\circ} \mathrm{C}$ dengan suhu udara ratarata yaitu $26,9^{\circ} \mathrm{C}$ dan tingkat kelembaban mencapai $81 \%$. Curah Hujan $(\mathrm{CH})$ tertinggi terjadi pada bulan Januari (419,5 mm), sedangkan $\mathrm{CH}$ terendah terjadi pada bulan Agustus $(17,4 \mathrm{~mm})$ dengan jumlah $\mathrm{CH}$ tahunan ratarata dalam 10 tahun yaitu 1808,1 mm. Jumlah hari hujan dalam setahun adalah 144 hari hujan. Hari hujan paling banyak terjadi pada bulan Januari yaitu sebanyak 24,1 hari, sedangkan hari hujan terendah terjadi pada bulan September yaitu sebanyak 3,9 hari (BMKG Stasiun Meteorologi Klas I Ngurah Rai Denpasar, 2015).

Tukad Badung di bagian wilayah Desa Pemogan memiliki ukuran yang tergolong lebar yakni sekitar $24 \mathrm{~m}$. Permukaan air sungai cenderung bertambah tinggi pada saat turun hujan namun masih di bawah level permukaan bantaran sekitar $50 \mathrm{~cm}$ (observasi lapangan, 14 Desember 2016).

Bantaran Tukad Badung di Desa Pemogan umumnya digunakan masyarakat sebagai tempat rekreasi, dengan aktivitas yang dilakukan diantaranya adalah memancing, berolahraga, hingga sekedar bersantai atau jalan-jalan baik secara individu maupun bersama keluarga. Pemerintah menggunakan bantaran untuk menggelar acara-acara pada waktu tertentu seperti lomba dayung (Wahyuni, wawancara 29 Januari 2017).

\subsection{Permasalahan}


Bantaran Tukad Badung di lokasi penelitian memiliki permasalahan penataan, kebersihan, dan fasilitas. Permasalahan yang dihadapi antara lain akses menuju bantaran kurang memadai, kurang tertatanya elemen softscape serta terdapat tanaman yang dapat membahayakan pengunjung, kondisi bantaran dan sungai yang kotor akibat sampah pengunjung dan sampah yang berasal dari bagian hulu sungai, dan belum tersedia fasilitas seperti bangku dan parkir kendaraan yang dapat mendukung aktivitas masyarakat.

\subsection{Konsep Dasar}

Metafora alam Bali dalam konsep ini mengambil inspirasi atau ide dari alam yakni teras persawahan dan deburan ombak pantai yang mendominasi dan menjadi ciri khas Pulau Bali. Pemilihan teras persawahan dan ombak pantai merupakan intepretasi dari suatu RTNHP yang sesuai dengan fungsinya yaitu sebagai wadah aktivitas masyarakat untuk rekreasi dan penyegaran, hal ini sejalan dengan pendapat Arrumaisa dan Suryawan (2014). Persawahan dan pantai merupakan tempat populer di Bali yang disenangi masyarakat sebagai tempat rekreasi maupun penyegaran, sehingga atas dasar pemikiran tersebut persawahan dan pantai dapat digunakan untuk konsep metafora. Pada dasarnya penggunaan bentuk teras persawahan dan ombak pantai kedalam desain RTNHP di bantaran Tukad Badung memiliki kesamaan sifat dan tujuan yaitu, terbuka, rekreatif, dan sifatnya menyegarkan, sehingga perpaduan ini mengandung arti metafora pada RTNHP yang menegaskan hubungan antara beberapa objek yang mempunyai kesamaan sifat. Penelitian ini juga mengadaptasi maskot flora Kota Denpasar yaitu Gardenia jasminoides (kaca piring/jempiring).

\subsection{Konsep Desain}

Konsep dasar yang telah dirumuskan dilanjutkan dengan konsep desain yang melibatkan simbol dan bentuk metafora alam Bali. Pada tahapan konsep desain ini mencakup penataan ruang, konsep sirkulasi, konsep penanaman, konsep perkerasan, dan konsep pencahayaan.

Konsep metafora teras persawahan merupakan kombinasi dalam wujud konseptual dan visual. Penggambaran bentuk teras persawahan kedalam desain bantaran ditampilkan pada bagian terpinggir bantaran yang berhadapan langsung dengan sungai. Interpretasi dari teras persawahan dimunculkan melalui bentuk arsitektur dengan mendesain tepi bantaran dengan bentuk teras menyerupai tangga (Gambar 2). Desain pinggiran bantaran yang berteras bertujuan agar pengguna lebih dekat dengan sungai, terutama untuk aktivitas yang memerlukan sungai sebagai sarana kegiatan seperti memancing. Desain teras tersebut juga dapat berfungsi sebagai tempat duduk.

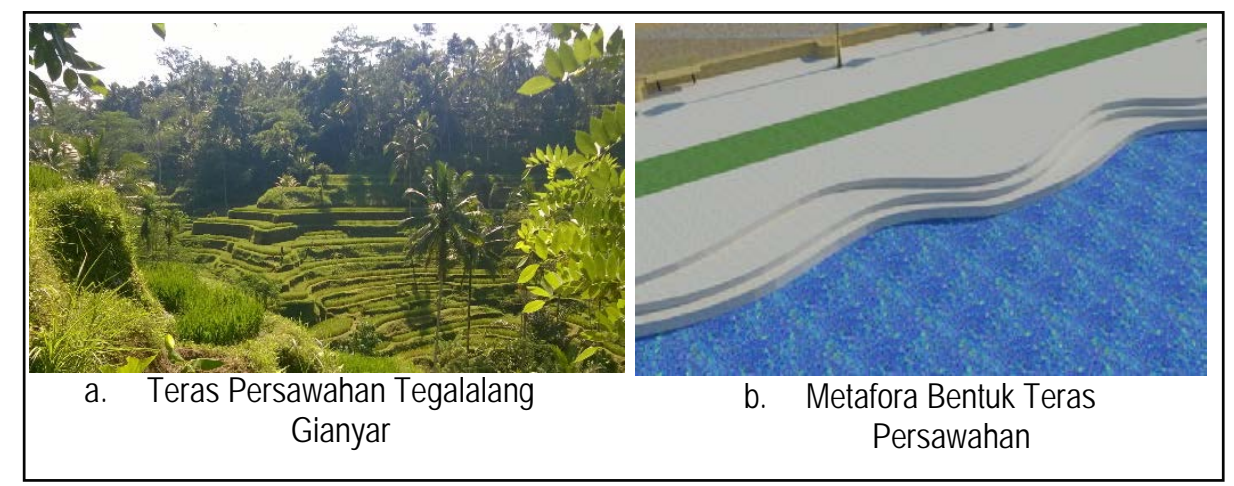

Gambar 2. Metafora Teras Persawahan

Adapun pengembangan bentuk dari metafora teras persawahan tersebut guna memberi aksen unik pada bantaran. Pengembangan metafora ini disebut carik uwug yang terinspirasi dari keadaan sawah usai pembajakan. Tanah sawah yang usai dibajak permukaannya cenderung tidak rata karena dilindas oleh traktor atau kerbau, maka metafora carik uwug didesain agar berkesan seperti tidak beraturan dan tidak rata pada permukaannya (Gambar 3). 


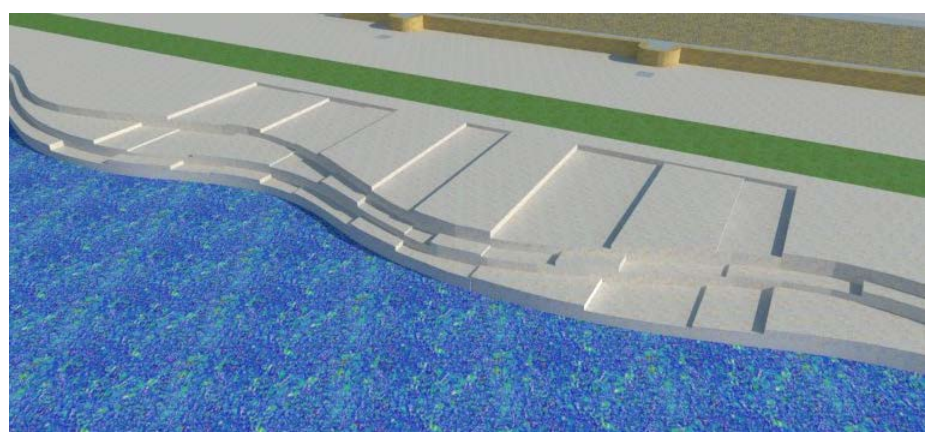

Gambar 3. Metafora Carik Uwug

Metafora ombak pantai dalam penelitian ini juga merupakan metafora kombinasi yang diwujudkan secara visual dan konseptual. Peletakan metafora ombak pantai yaitu pada bagian area penanaman yang berfungsi sebagai pagar. Metafora ini juga dapat diaplikasikan pada bentuk massa tanaman strata semak (Gambar 4). Tinggi rendah tanaman diatur hingga mendapat bentuk yang bersinergi dengan pagar, sehingga menunjukkan harmoni antara elemen softscape dan hardscape.

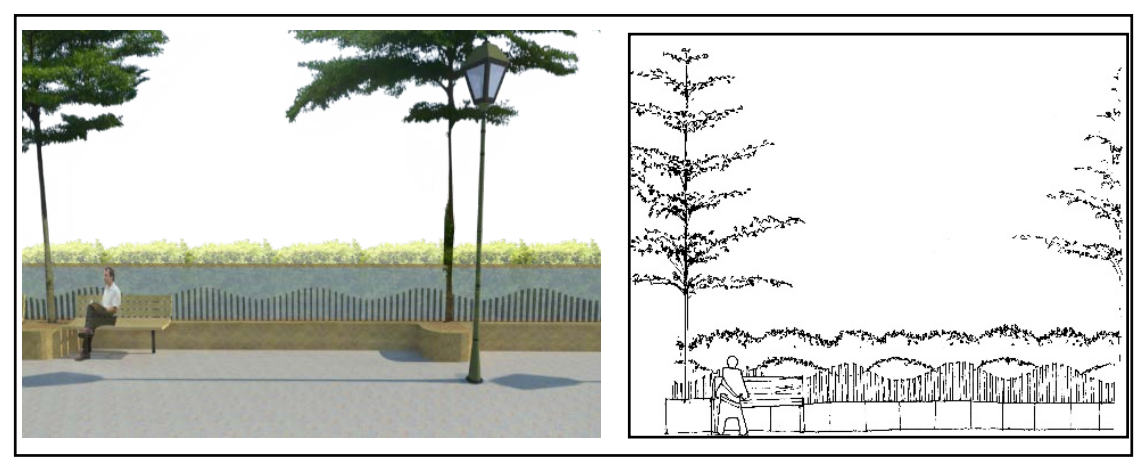

Gambar 4. Metafora Ombak Pantai

\subsubsection{Penataan Ruang}

Penataan ruang merupakan peta pemanfaatan ruang bantaran Tukad Badung di kawasan Desa Pemogan dengan mendesain ruang-ruang yang merupakan penjabaran dari fungsi yang didesain pada tapak. Penataan ruang mengikuti pola alami sungai yang memanjang, sehingga muncul ruang-ruang seperti pedestrian, area vegetasi, dan area memancing yang bentuknya memanjang mengikuti kondisi tapak.

\subsubsection{Konsep sirkulasi}

Sirkulasi pada tapak terdiri dari sirkulasi manusia dan kendaraan. Sirkulasi kendaraan hanya dibatasi sampai pada area parkir kendaraan yang masing-masing berada di utara dan selatan. Parkir utara merupakan parkir untuk kendaraan roda dua, sedangkan parkir selatan untuk kendaraan roda empat. Pertimbangan penempatan parkir kendaraan roda empat adalah ketersediaan ruang untuk manuver kendaraan dan pertimbangan akses dari jalan utama seperti Jalan By Pass Sunset Road dan Jalan By Pass Ngurah Rai. Sirkulasi manusia meliputi akses menuju bantaran, area bangku, pedestrian, area rumput, dan area memancing. Sirkulasi manusia dibuat lurus memanjang mengikuti pola alami sungai serta dua arah, seperti sirkulasi pada area pedestrian.

\subsubsection{Konsep Penanaman}

Tanaman strata semak menggunakan Gardenia jasminoides yang peletakannya terinspirasi dari Tari Sekar Jempiring yang merupakan tari penyambutan. Berdasarkan filosofi dari Tari Sekar Jempiring yang merupakan tari penyambutan, maka peletakan Gardenia jasminoides yaitu pada area masuk dengan tujuan untuk menyambut pengunjung yang datang ke bantaran Tukad Badung. Contoh tanaman strata semak lainnya yang dapat digunakan untuk penambah nilai estetika adalah Syzygium oleina, Codiaeum variegatum, Cordyline terminalis, Philodendron cellum, Osmoxylon liniare. Peletakan tanaman tersebut diletakkan dengan 
komposisi berselang-seling pada area penanaman dengan memanfaatkan daun tanaman yang berbeda warna. Tanaman dengan daun merah dan hijau dapat digunakan sebagai contoh untuk mendapatkan efek kontras sehingga pola penanaman terlihat secara jelas. Tanaman semak yang dapat menyerap polusi juga dapat digunakan contohnya Syzygium oleina. Tanaman penyerap polusi dapat diletakkan pada bagian terluar area penanaman yang berbatasan langsung dengan jalan.

Tanaman strata pohon diletakkan secara berjajar pada area penanaman mengikuti pola alami sungai. Penggunaan tanaman strata pohon menggunakan tanaman yang karakteristiknya dapat mendukung dan sesuai dengan konsep metafora teras persawahan. Pemilihan tanaman dengan tajuk bertingkat dapat digunakan untuk menyelaraskan tanaman dengan bentuk sawah berteras dari metafora teras persawahan. Pemilihan tanaman juga mempertimbangkan fungsi lainnya, seperti fungsi ekologis, estetika, dan kenyamanan. Tanaman yang dapat menyerap polusi, serta memiliki nilai estetika dan menambah kenyamanan, kegunaanya diperlukan kedalam desain. Contoh tanaman strata pohon yang dapat dipilih adalah Terminalia mantaly. Jenis rumput yang digunakan pada konsep penanaman mempertimbangkan aspek estetika dan kekuatan dari rumput tersebut, contohnya adalah Zoysia matrella.

\subsubsection{Konsep Perkerasan}

Konsep perkerasan pada bantaran menggunakan material paving blok pada area aktivitas seperti memancing, pedestrian, bangku, akses pejalan kaki, dan area parkir kendaraan. Pengaplikasian paving blok pada tapak lebih praktis dan mudah dibandingkan dengan paving lainnya contohnya paving dengan bentuk segi enam. Kelebihan lain dari paving blok yaitu terletak pada aspek keamanan, yang mana memiliki tekstur kasar sehingga tidak licin. Contoh paving blok yang dapat digunakan adalah paving blok dengan ukuran besar dan memiliki bentuk persegi panjang. Pada area parkir kendaraan tidak menggunakan paving blok dengan ukuran besar, karena paving blok tersebut berpotensi patah atau rusak pada saat dilintasi kendaraan. Paving blok dengan ukuran kecil lebih sesuai digunakan pada area parkir kendaraan. Pertimbangan dari pemilihan paving blok dengan ukuran lebih kecil yakni jika dipasang secara masal pada tapak akan lebih kuat terhadap kendaraan yang melintas di atasnya. Pemilihan material ramp kendaraan mempertimbangkan aspek keamanan yakni menggunakan material yang tidak licin agar kendaraan tidak mudah tergelincir. Contoh material untuk jalur ramp dapat menggunakan semen poles. Tingkat kekasaran tekstur pada semen poles dapat diatur sesuai keperluan pada saat pembuatannya, sehingga semen poles merupakan material yang tepat digunakan pada ramp kendaraan.

\subsubsection{Konsep Pencahayaan}

Konsep pencahayaan yang digunakan pada bantaran adalah pencahayaan yang fungsional yaitu dapat memenuhi fungsi keselamatan, keamanan, dan keindahan. Pencahayaan dengan fungsi keamanan terletak pada area pedestrian, akses pejalan kaki, jembatan, dan area parkir kendaraan. Pada area pedestrian diletakkan pencahayaan dengan fungsi keamanan sekaligus estetis. Pencahayaan didesain mengarah ke segala arah, baik ke arah akses, bangku, pedestrian, maupun ke tepi sungai dengan tinggi sekitar 3,6 m. Pada area akses pejalan kaki dan jembatan di tapak yang terpisah pada bagian selatan bantaran barat menggunakan pencahayaan dengan tinggi skitar $60 \mathrm{~cm}$ yang menyorot lantai tapak guna mendapat nilai estetika. Pada area parkir pencahayaan yang digunakan yaitu mengarah ke bawah dengan tinggi sekitar $9 \mathrm{~m}$.

\subsubsection{Konsep Desain Lansekap Bantaran Tukad Badung}

Konsep Desain Lansekap Bantaran Tukad Badung penelitian ini merupakan hasil dari konsep desain yang meliputi penataan ruang, konsep sirkulasi, konsep penanaman, konsep perkerasan, dan konsep pencahayaan. Konsep desain dapat dilihat pada Gambar 5. 


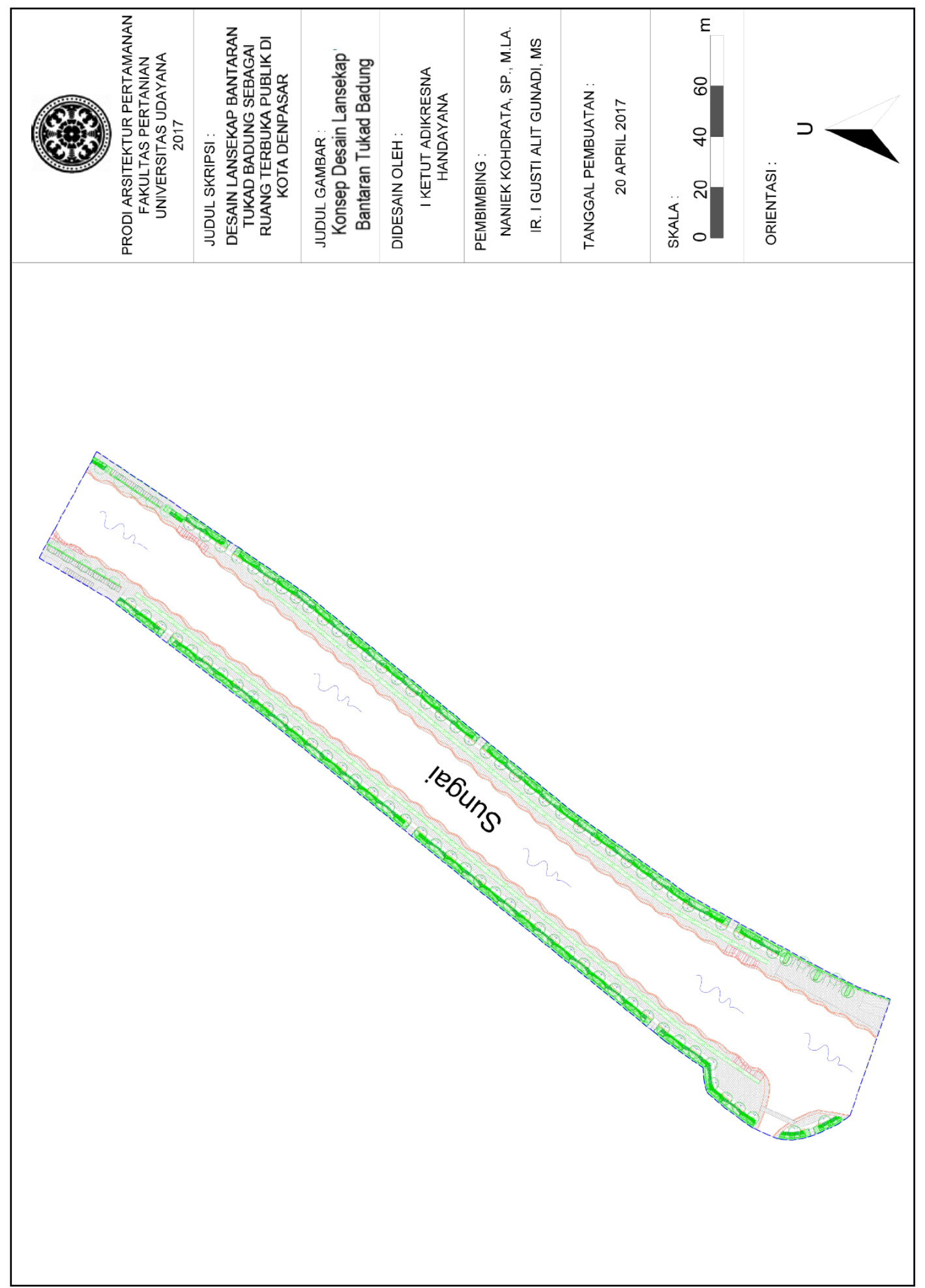

Gambar 5. Desain Lansekap Bantaran Tukad Badung sebagai Ruang Terbuka Non Hijau Publik di Kota Denpasar

\section{Simpulan dan Saran}

\subsection{Simpulan}

Permasalahan yang terdapat di Bantaran Tukad Badung di kawasan Desa Pemogan untuk didesain menjadi RTNHP yaitu permasalahan pada akses serta fisik akses menuju bantaran yang kurang memadai, terdapat tanaman-tanaman yang peletakannya kurang tertata dan membahayakan pengguna serta berpotensi 
merusak struktur bangunan sungai, tanah menjadi berlumpur pada saat hujan, permasalahan sampah pada sungai dan bantaran, belum tersedia fasilitas pendukung aktivitas masyarakat, dan belum tersedianya tempat parkir.

Konsep Desain Lansekap bantaran Tukad Badung yang digunakan adalah metafora alam Bali yang mengadopsi bentuk teras persawahan dan ombak pantai serta mengambil pemikiran maskot flora Kota Denpasar. Konsep yang dirumuskan dilanjutkan dengan konsep penataan ruang, konsep sirkulasi, konsep penanaman, konsep perkerasan, dan konsep pencahayaan. Konsep desain pada penelitian juga didukung oleh sintesis yang dirumuskan seperti menyediakan tempat sampah pada bantaran dan jaring pada sungai untuk mengatasi masalah sampah pada bantaran dan sungai. Pemilihan bentuk teras persawahan dan ombak pantai kedalam desain RTNHP di bantaran Tukad Badung karena terdapat kesamaan sifat dan tujuan yaitu, terbuka, rekreatif, dan sifatnya menyegarkan, sehingga perpaduan ini mengandung arti metafora pada RTNHP yang menegaskan hubungan antara RTNHP dengan teras persawahan dan ombak pantai yang mempunyai kesamaan sifat.

\subsection{Saran}

Hasil dari redasain lansekap bantaran Tukad Badung di kawasan Desa Pemogan ini dapat menjadi referensi alternatif bagi konsep pengembangan daerah penataan bantaran sungai dan dapat menjadi masukan bagi pemerintah kota dalam masalah desain Ruang Terbuka Non Hijau Publik khususnya pada bantaran Tukad Badung di Desa Pemogan.

\section{Daftar Pustaka}

Arrumaisa, N. dan W. A. Suryawan. 2014. Pendekatan Rancang Metafora dalam Perancangan Kafe dan Karaoke. Surabaya. Jurnal Sains dan Seni Pomits Vol. 3, No. 2.

Badan Meteorologi Klimatologi dan Geofisika. 2015. Pelayanan Jasa Informasi Klimatologi. Stasiun Meteorologi Klas I Ngurah Rai. Denpasar.

Dinas Kependudukan dan Pencatatan Sipil Kota Denpasar. 2016. Jumlah Penduduk Kota Denpasar per Kecamatan. Tersedia online di: http://www.denpasarkota.go.id (Diakses tanggal 9 Juli 2017).

Supraptomardjo, M. 1970. Peta Tanah Tinjau Pulau Bali. Junus Dai.

Kementrian Pekerjaan Umum Dan Perumahan Rakyat Republik Indonesia, 2017. Pembangunan Infrastruktur Asian Games XVIII Sudah Memenuhi Syarat Baik Kualitas Dan Waktu. Tersedia online di: www.pu.go.id (Diakses tanggal 16 April 2017). 